\title{
Artificial Neural Network Model for Estimation of Wear and Temperature in Pin-disc Contact
}

\author{
Abdul Kareem F. Hassan, Sara Mohammed* \\ College of Engineering, Basra University, Iraq
}

Copyright $(2016$ by authors, all rights reserved. Authors agree that this article remains permanently open access under the terms of the Creative Commons Attribution License 4.0 International License

\begin{abstract}
This work aims to investigate experimentally the parameters affecting on the wear debris and the temperature rise due to friction as well as developing the artificial neural network model (ANN) using MATLAB program for predicting the wear, and temperature of disc and pad. Two types of disc made from aluminum and steel are slipping against pad and carried out under dry conditions at different time, rotational speed, and load to examine the wear. The results show that the wear and temperature are increased with increasing the sliding speed, and load or contact time. In addition, the wear of pad is higher when it's contact with aluminum disc, while the temperature of pad is higher when its contact with steel. The ANN model was successfully shows that there is a high ability to predict the wear and temperature as well as the results of model corresponding with the experimental results.
\end{abstract}

Keywords Abrasive Wear, Artificial Neural Networks, Frictional Wear

\section{Introduction}

Wear is the surface damage or removal of material from one or both of two solid surfaces in relative motion (sliding, rolling, impact) [1]. The wear and friction are not intrinsic properties of a material but characteristic of the total engineering system and operating environment. Therefore, any change in load, temperature, and speed can have a significant effect on the type of wear or the wear rate of a component [2]. Among many failure modes associated with materials components. Wear presents a unique challenge to the designer and developer of mechanical components. Wear is commonly undesirable deterioration of component through the removal of material from its surface which is widely occurs in the machining operation [3]. Therefore, it is important to establish an optimized model for the prediction of wear during operations. Artificial neural network (ANN) has provided an exciting alternative method for solving a variety of problems in different fields of science and engineering. Artificial Neural Networks (ANNs) are revolutionary computing paradigms that try to mimic the biological brain [4]. These ANNs are modeling techniques that are especially useful to address problems where solutions are not clearly formulated or where the relationships between inputs and outputs are not sufficiently known [5]. The ANN has been used successfully by many investigators and shows a high ability to predict the wear [6-9].

Many researchers have been studied the parameters that effects the wear of various materials and observed that the wear rates increased with increasing the sliding speed and normal load [10-13], while some of them have been focused on the friction temperature and its related to wear. They found that the friction temperature increased with increasing normal load and sliding speed as well as the wear volume increased with increasing the friction temperature $[14,15]$. The purpose of this study is to create the artificial neural networks to estimate the wear volume of pad contact with rotational disc under different pressure, rotational speed and duration of rubbing by using two types of disc materials which are steel and aluminum. Moreover, the temperature rise in disc and pad materials due to frictions during the wear tests was also considered too.

\section{Experimental Work}

The experimental work was carried out on two pin-disc arrangement by using friction and wear machine type ET97 that shown in figure 1. This machine is working on $3 \mathrm{HP}$ power and contain a disc fixed on a horizontal rotating shaft and two pads ( right pad, left pad) each one fixed on a screw to move towards the disc in horizontal movement when the pressure applied through it. Moreover, stepped pulley has been used in this machine in order to change the speed of machine at the range of (100-2200) rpm and the load (pressure) can be applied in the range of (1-10) bars. The machine has been designed with ability for replacement of the disc and pad material. The pair of pad made of non-asbestos material cut from brake pad of Toyota car 
according to OME (original equipment manufacture) as shown in figure 2 were tested against steel and aluminum discs. The pads are manufactured with diameter of $35 \mathrm{~mm}$ and thickness of $12 \mathrm{~mm}$ as shown in figure.3. Two discs metals used both with outer diameter of $100 \mathrm{~mm}$, inner diameter of $30 \mathrm{~mm}$ and thickness of $12 \mathrm{~mm}$. The test is conducted at different pressures which are 2, 3, 4, and 5 bar, rotational speeds equal to $400,800,1100$, and $1500 \mathrm{rpm}$ and contact time equal to 1, 2, and $3 \mathrm{~min}$. Wear was measured by weighing the specimens before and after the test by using an electronic balance with accuracy of $0.1 \mathrm{mg}$ and calculate the wear as the difference of their weight. The temperature rise on the contacting surface of the pad and disc is recorded before and after each trail by infrared thermometer type IP54. It was measured at a specific point on the disc, which was not the higher temperature of contacting surface, but provides sufficient evidence of rise in temperature. After each experiment the surfaces are cleaned to remove dirt and wear debris to get the maximum contact. The effect of each parameter has been studied by conducted number of trails through changing one parameter and keeping the other constant. The detail experimental conditions are shown in table 1 .

Table1. Experimental conditions

\begin{tabular}{|cl|c|}
\hline No. & Parameters & Operating Conditions \\
\hline 1. & Normal load & $2,3,4,5$ bar \\
2. & Rotational speed & $400,800,1100,1500 \mathrm{rpm}$ \\
3. & Duration of rubbing & $1,2,3$ minutes \\
4. & Surface condition & Dry \\
5. & Material of pad & Non-asbestos \\
6. & Materials of discs & (i) Steel \\
\end{tabular}

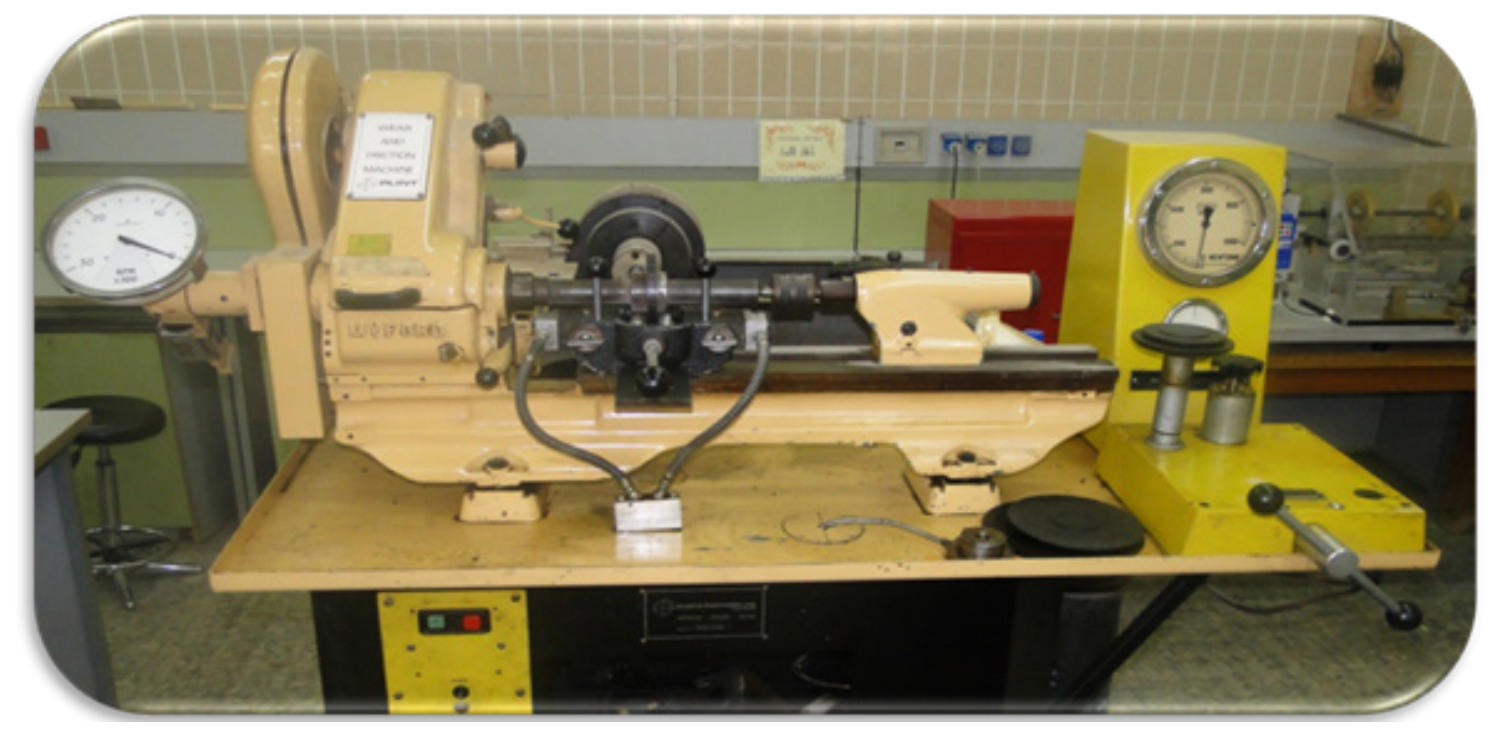

Figure 1. Friction and wear machine 


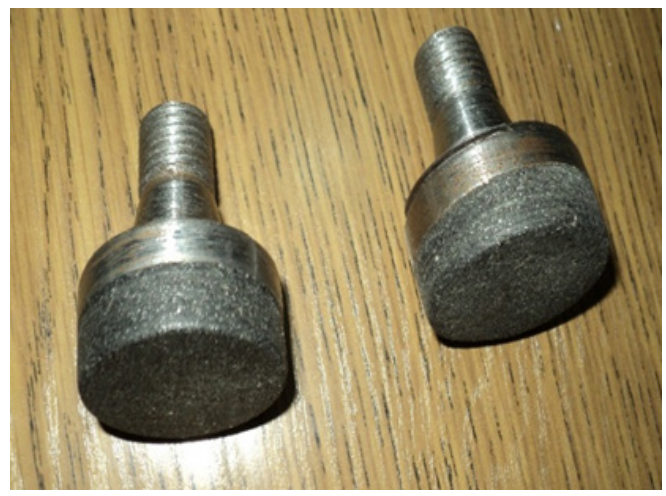

Figure 2. The pad

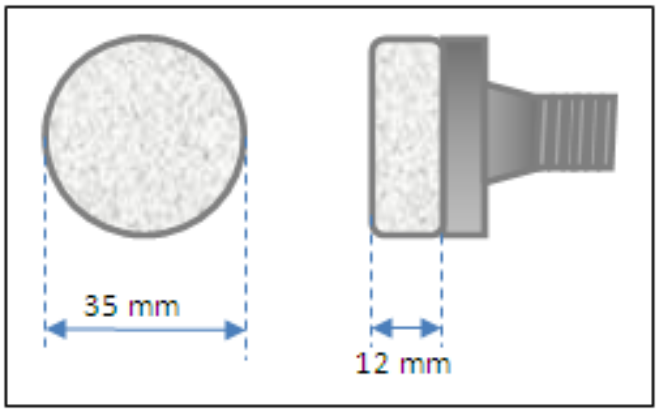

Figure 3. Pad dimensions

\section{Neural Network Model Development and Optimization}

Artificial neural networks are considered as artificial intelligence modeling techniques which have a highly interconnected structure similar to brain cells of human neural networks. It is consist of a large number of simple processing elements called neurons, which are arranged in different layers in the network and can be classified as input layer, output layer and one or more hidden layers [16]. In this work, artificial neural network model is develops to predict the wear, temperature of disc and pad by known five affecting parameters: rotational speed, pressure, contact time, initial disc temperature, initial pad temperature. There is no equations which connecting these different factors to calculate the wear and temperatures so it's become so important to develops such a model. Two model were developed, the first one predict the temperatures and wear of the pad as it is contact with steel disc and the second model predict the temperatures and wear of the pad as it is contact with aluminum disc. The experiment wear test consist of 45 data were used to develop a neural network model, 36 of them were used as training and the rest 9 have been used for testing. The numbers of training data are taken approximately to be equal to $80 \%$ of the total data, while the numbers of testing data are taken randomly to be approximately equal to $20 \%$ of the total database. The development of ANN requires the selection of number of hidden layers and the neurons in each of hidden layer from the best activation function, the trial and error have been carried out to choose the best number of hidden layers and the number of neurons in each hidden layer [21].

In the present work, the network was tested for different activation function with one and two hidden layers configurations and an increasing the number of nodes in each hidden layer. The range of parameters used to produce training data is shown in Table 2.

Table 2. The range of input and output parameters

\begin{tabular}{|c|c|c|c|c|}
\hline & \multirow{2}{*}{ Parameters } & \multirow{2}{*}{ Units } & \multicolumn{2}{|c|}{ Range of parameters } \\
\hline & & & From & To \\
\hline \multirow{5}{*}{$\begin{array}{c}\text { Input } \\
\text { Parameters }\end{array}$} & Rotational speed & RPM & 400 & 1500 \\
\hline & Pressure & bar & 2 & 5 \\
\hline & Time & $\mathrm{sec}$ & 60 & 180 \\
\hline & $\begin{array}{c}\text { Initial temperature of } \\
\text { steel disc }\end{array}$ & ${ }^{\circ} \mathrm{C}$ & 18.4 & 80.3 \\
\hline & $\begin{array}{c}\text { Initial temperature of } \\
\text { the pad }\end{array}$ & ${ }^{\circ} \mathrm{C}$ & 19.3 & 51.3 \\
\hline \multirow{3}{*}{$\begin{array}{c}\text { Output } \\
\text { Parameters }\end{array}$} & Weight loss & gm & 0.00065 & 0.0153 \\
\hline & $\begin{array}{c}\text { Final temperature of } \\
\text { steel disc }\end{array}$ & ${ }^{\circ} \mathrm{C}$ & 22.1 & 123 \\
\hline & $\begin{array}{c}\text { Final temperature of } \\
\text { the pad }\end{array}$ & ${ }^{\circ} \mathrm{C}$ & 20.1 & 140.7 \\
\hline
\end{tabular}

\subsection{Selection the number of neurons and the activation function in one hidden layer}

The number of neurons in one hidden layer was selected by trial and Error, different neurons in each hidden layer were used for different activation functions. It is started with a relatively small number of neurons (4 neurons) and increases until the approximation is satisfied for the network. It is observed that the best performance and correlation coefficient for both training and testing were achieved with 5 nodes in the hidden layer with activation function as hyperbolic tangent (tansig) and (purelin) function and (trainrp) as training function.

\subsection{Selection the number of nodes and the activation function in one hidden layer}

The numbers of neurons in two hidden layers are also selected by using trial and error with different neurons in each hidden layer starting from 5 to 8 in each hidden layer. The performance and the regression of these networks for both training and testing data are considered. It is found that the network with (8-7) nodes (8 nodes in the first hidden layer and 7 in the second ) with training function as Conjugate Gradient type (trainscg) gives better performance and correlation coefficient for both training and testing than the other.

After finding out the best function with the number of neurons in one and two hidden layers, the performance of the theses networks is compared in order to find the best one as shown in figure 4. It is clear that two hidden layers with training function (trainscg) and 8-7 nodes gives the best performance and a correlation coefficient, therefore, it is selected as the best network in the present work. 


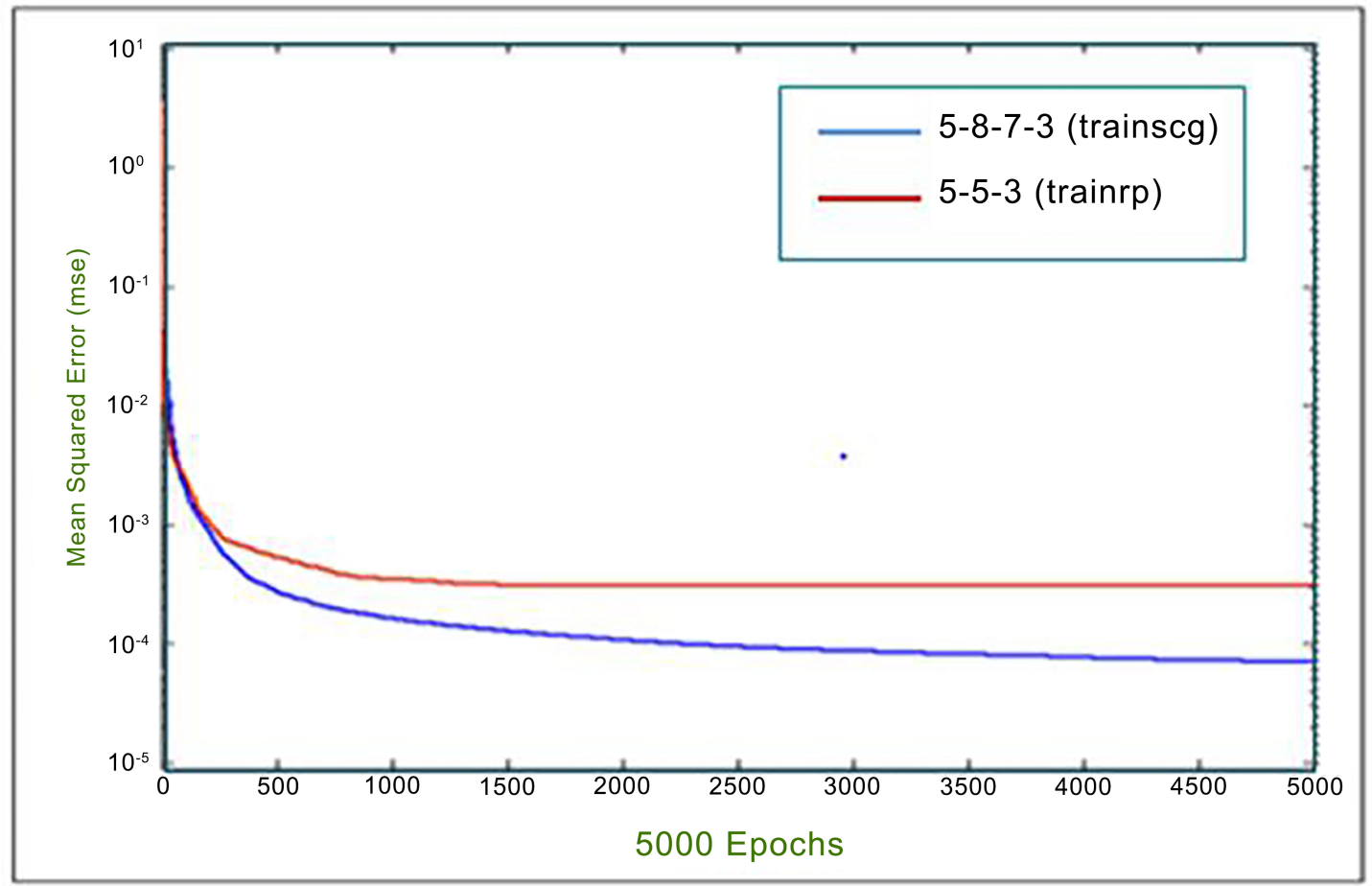

Figure 4. The performance of best one and two hidden layers

Table 3. The correlation coefficients and mean square error MSE

\begin{tabular}{|c|c|c|c|c|c|c|c|c|c|c|}
\hline \multirow{2}{*}{ ANN Model } & \multirow{2}{*}{$\begin{array}{c}\text { Node } \\
\text { No. }\end{array}$} & \multirow{2}{*}{ Training } & \multicolumn{4}{|c|}{ Training data (80\%) } & \multicolumn{4}{|c|}{ Testing data (20\%) } \\
\cline { 5 - 12 } & Function & MSE & R1 & R2 & R3 & MSE & R1 & R2 & R3 \\
\hline Aluminum & $5-8-7-3$ & trainscg & 0.000024 & 0.99978 & 0.99992 & 0.99993 & 0.032 & 0.98964 & 0.96789 & 0.99141 \\
\hline Steel & $5-8-7-3$ & trainscg & 0.000009 & 0.9999 & 0.9999 & 0.9782 & 0.0101 & 0.9682 & 0.9013 & 0.9998 \\
\hline
\end{tabular}

Figure 5, shows the configuration of the suggested artificial neural network (5-8-7-3) neurons ( 8 neurons in the first hidden layer and 7 in the second. The selection of a number of the hidden layers and the neurons in each hidden layer has been done for both Steel and Aluminum models.

The regression analysis between the output of neural network and the corresponding target for training and testing data are shown in figures $6,7,8,9,10$ and 11 for wear, steel disc temperature and pad temperature, respectively. The predicting values compared with the target values and an excellent agreement has been noted. The correlation coefficient (R-value) between the outputs and targets, it can be defined as a measure of how well the variation in the output is explained by the targets. If this number is equal to 1 , then there is a perfect correlation between targets and outputs. The broken line indicates the best line fit and the solid line indicates the perfect fit (output equals targets). The experimental and predicted values are very close to each other, which mean that the proposed ANN model has high correlation factor for prediction of wear for training and testing $\mathrm{R}=0.99978$ and $\mathrm{R}=0.98964$, respectively as shown in figures 6 and 7. On the other hand, disc temperature $\mathrm{R}=0.99992$ and $\mathrm{R}=0.96789$ as training and testing for disc temperature, respectively as shown in figure 8 and 9 . The pad temperature has $\mathrm{R}=0.99993$ for training and 0.99141 for testing as shown in figure 9 and 10. Table 3 clarifies the correlation coefficients and the mean square error (MSE) of the two ANN models for predicting the wear and temperature of disc and pad in training and testing.

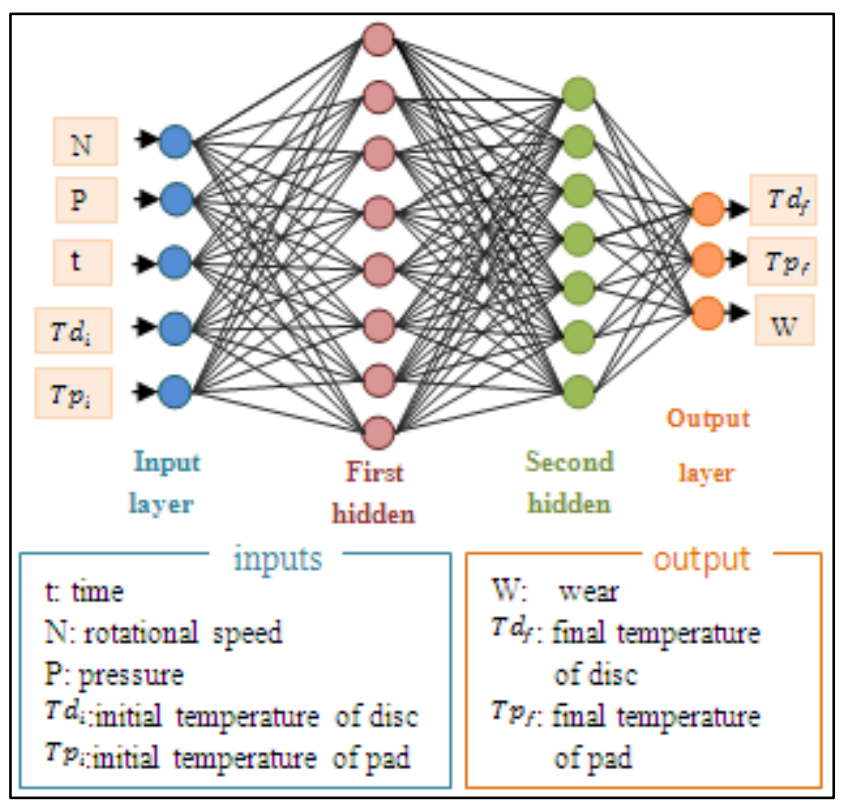

Figure 5. Configuration of the neural network (5-8-7-3) 


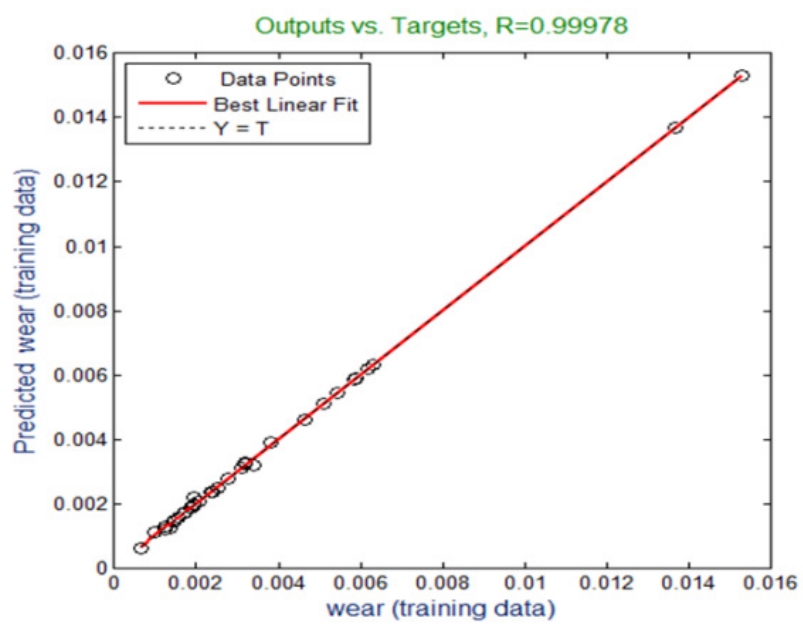

Figure 6. The regression analysis of wear for training data

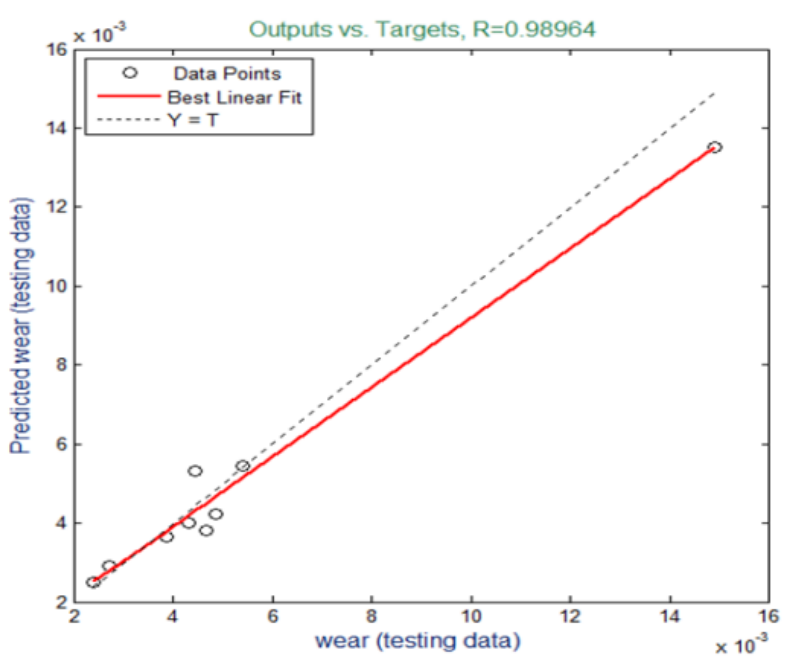

Figure 7. The regression analysis of wear for testing data

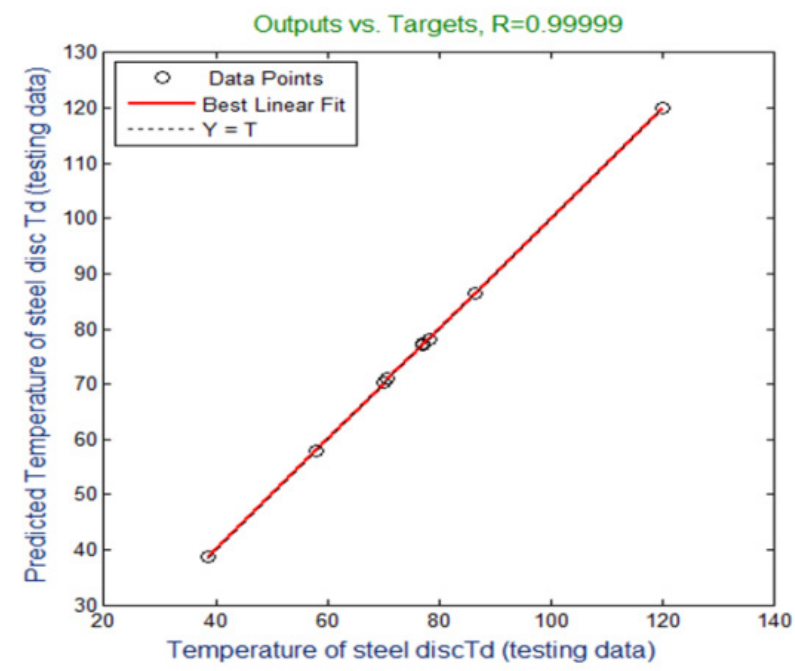

Figure 8. The regression analysis of steel disc temperature for training data

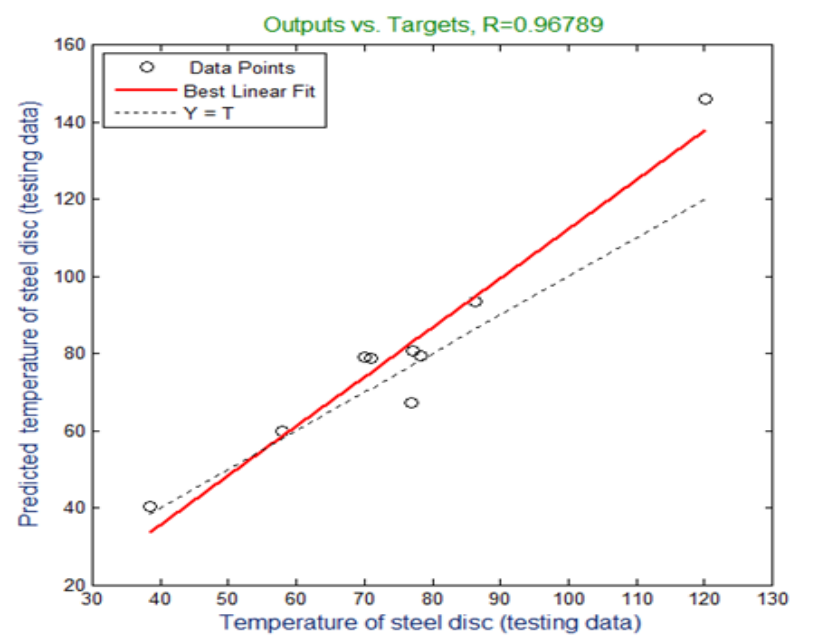

Figure 9. The regression analysis of steel disc temperature for testing data

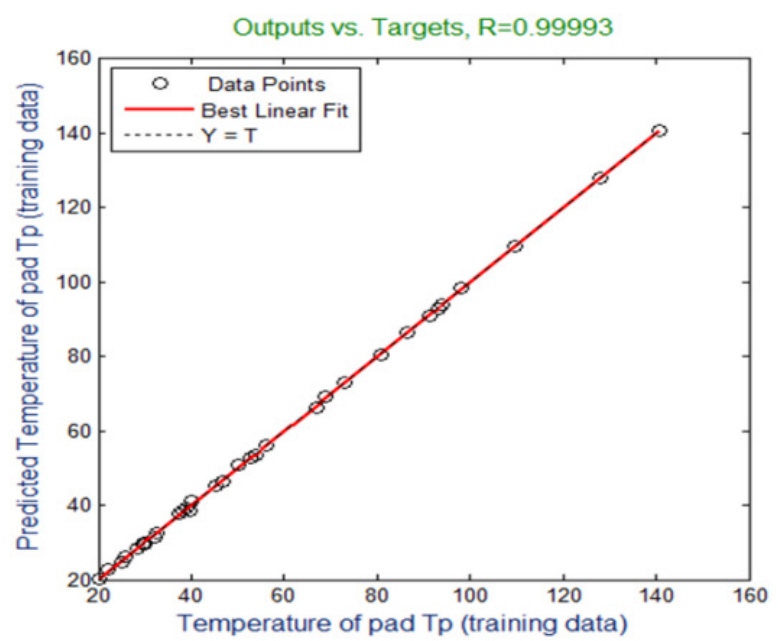

Figure 10. The regression analysis of pad temperature for training data

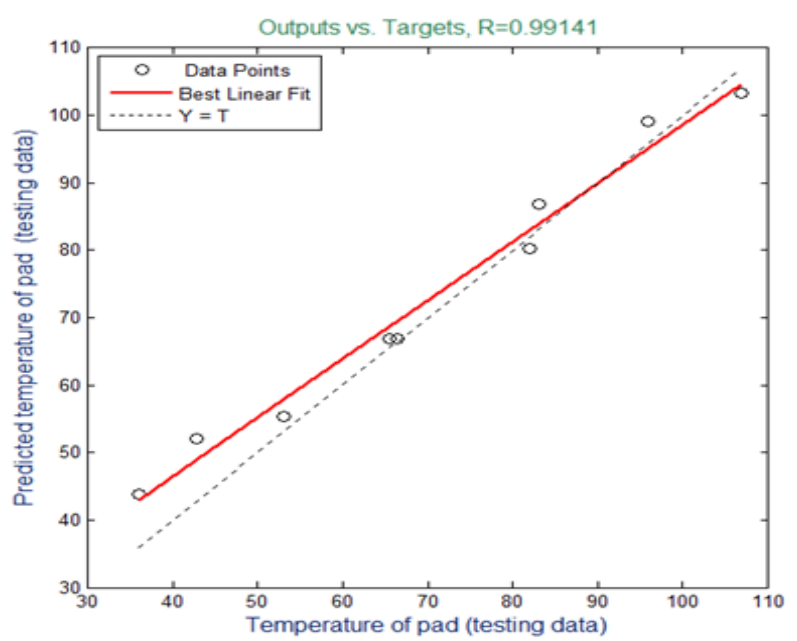

Figure 11. The regression analysis of pad temperature for testing data 


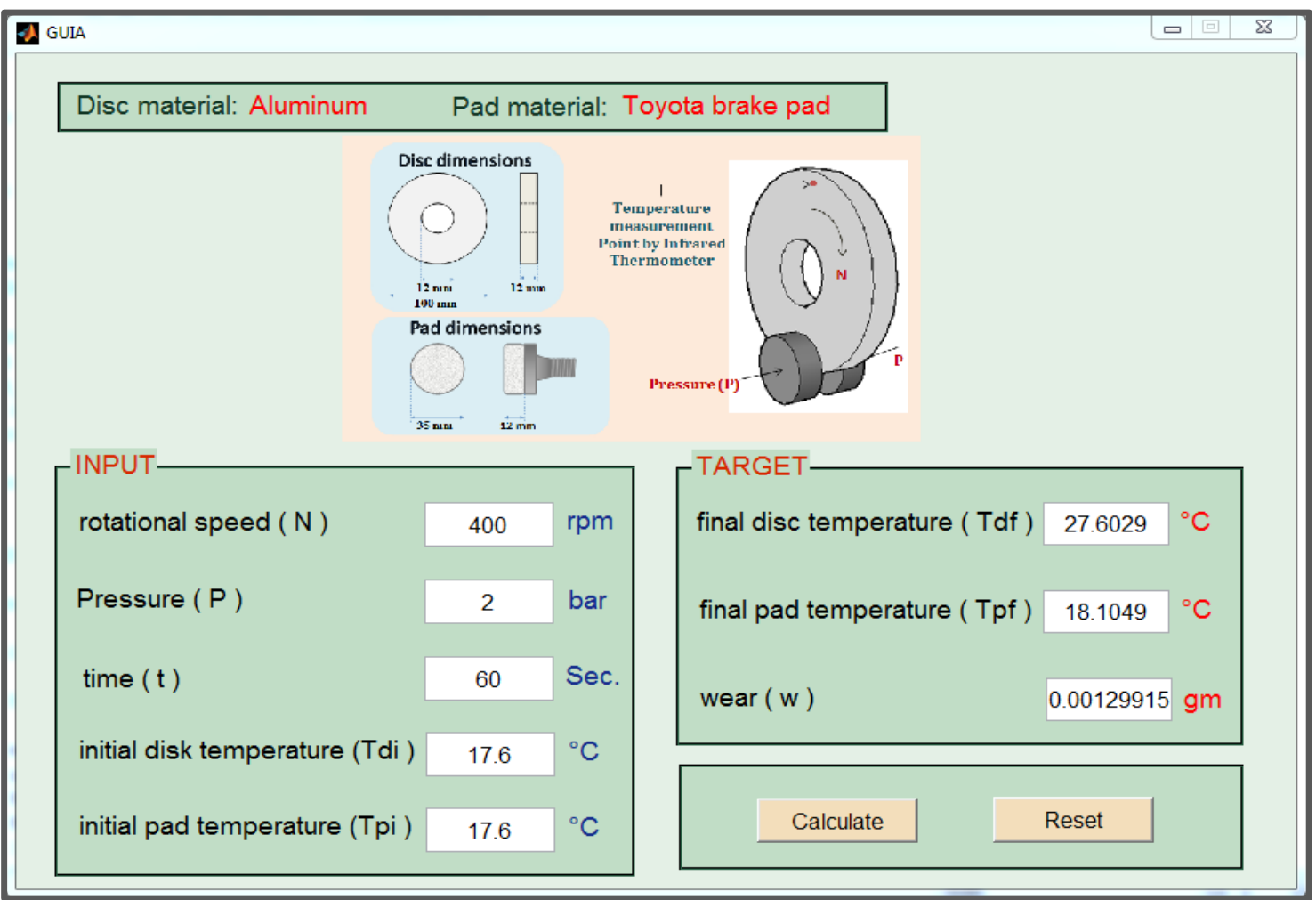

Figure 12. GUI of aluminum disc case for prediction

A graphical user interface is a graphical interface to a program.The GUI typically contains controls such as menus, toolbars, buttons and sliders it can make the program easier to use .The GUI acts in a predictable manner .Figure 12 shows a window provided from the input data: rotational speed, pressure, time, initial steel disc Temperature and initial pad Temperature and the output data: wear, final steel disc Temperature and final pad temperature.

\section{Results and Discussion}

\subsection{Experimental}

Friction and wear test were carried out on pad to determine the weight losses of the pad when one of the effective parameters is changed (i.e rotational speed, pressure, time) and the weight losses when the contact material replaced. In addition, the rise of temperature of pad that happened due to the friction between the disc and pad was investigated too. The experimental results of wear test of steel and aluminum including the wear, temperature of disc and pad are shown in Figures 13-18

\subsubsection{Effects of pressure on wear and temperature rise}

The load has a significant effect on wear in case of using steel disc at pressure equal to 2 bars with rotational speed of $400 \mathrm{rpm}$, and contact time for $1 \mathrm{~min}$. The weight loss or wear is equal to $0.00065 \mathrm{gm}$, while when pressure increased to 4 bar, rotational speed to $1500 \mathrm{rpm}$, and contact time to $3 \mathrm{~min}$, the weight loss has become $0.0153 \mathrm{gm}$ as shown in figure 13 . In other words, any rise in the value of load on the pad leads to an increase in the wear because the actual area of contact would increase towards the nominal contact area, resulting in increased frictional force between two sliding surfaces. The increased frictional force and real surface area in contact cause higher wear. This means that the shear force and frictional thrust are increased with increase of applied load and these increased in values accelerate the wear rate [17]. The increase in pressure also leads to considerable increase in temperature of both disc and pad because the pressure (load) produce work and this work is converted to heat energy so increase pressure mean more heat is being released and more heat means higher Temperature [18] as shown in figures 14 and 15. The same behavior can be noted in the case of using aluminum disc as shown in figure 16, 17, and 18.

\subsubsection{Rotational speed effects}

Increasing rotational speed can cause more debris or wear as presented in figures 13 . The wear debris increase when the duration of rubbing is constant for all rotational speed, while the length of rubbing is more for higher rotational speed.The reduction of shear strength of the material and increased true area of contact between contacting surfaces may play some role in the higher wear rate at higher rotational speed [19]. Also, it was found that the disc and pad temperature increased with increasing of rotational speed because the frictional energy is converted to heat energy which leads to rise in temperature as shown is figures 14 and 15. 


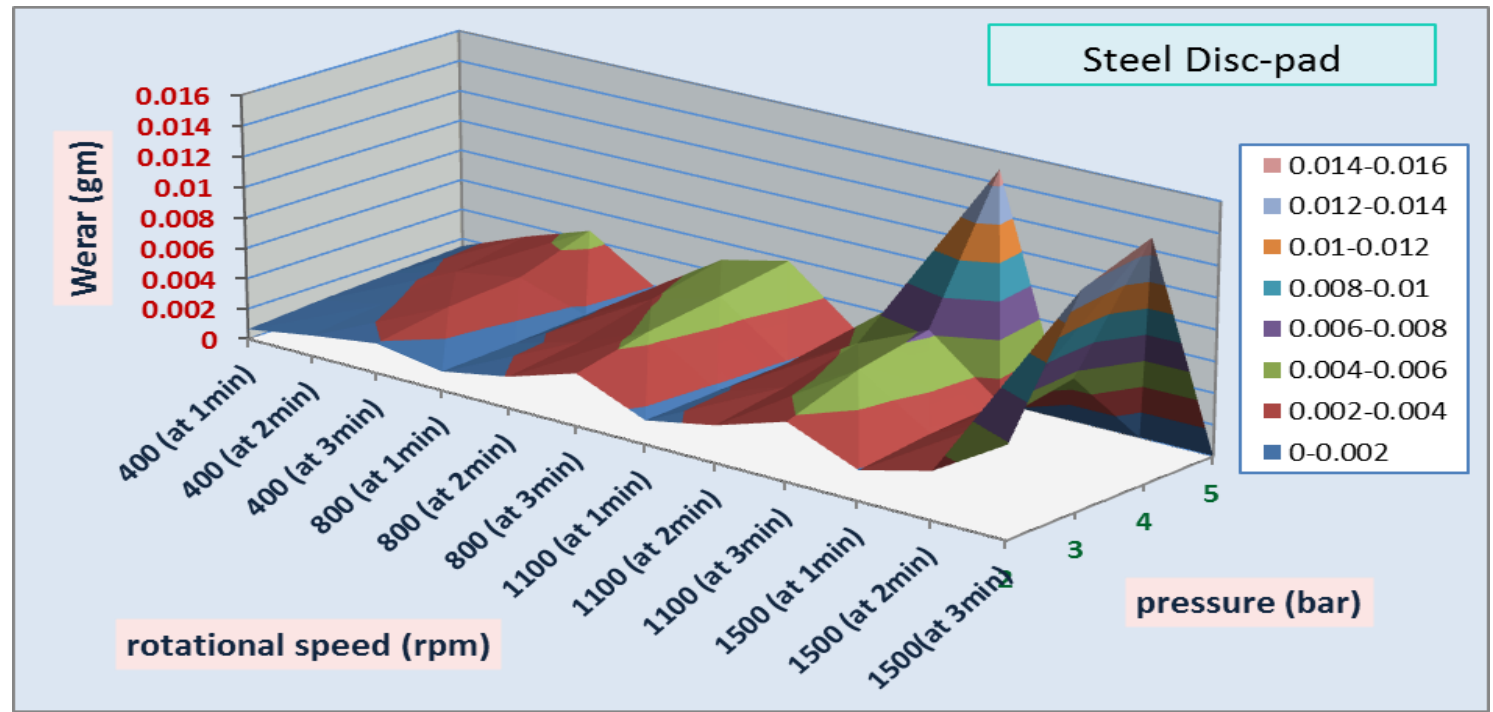

Figure 13. Effects of both rotational speed and pressure on wear

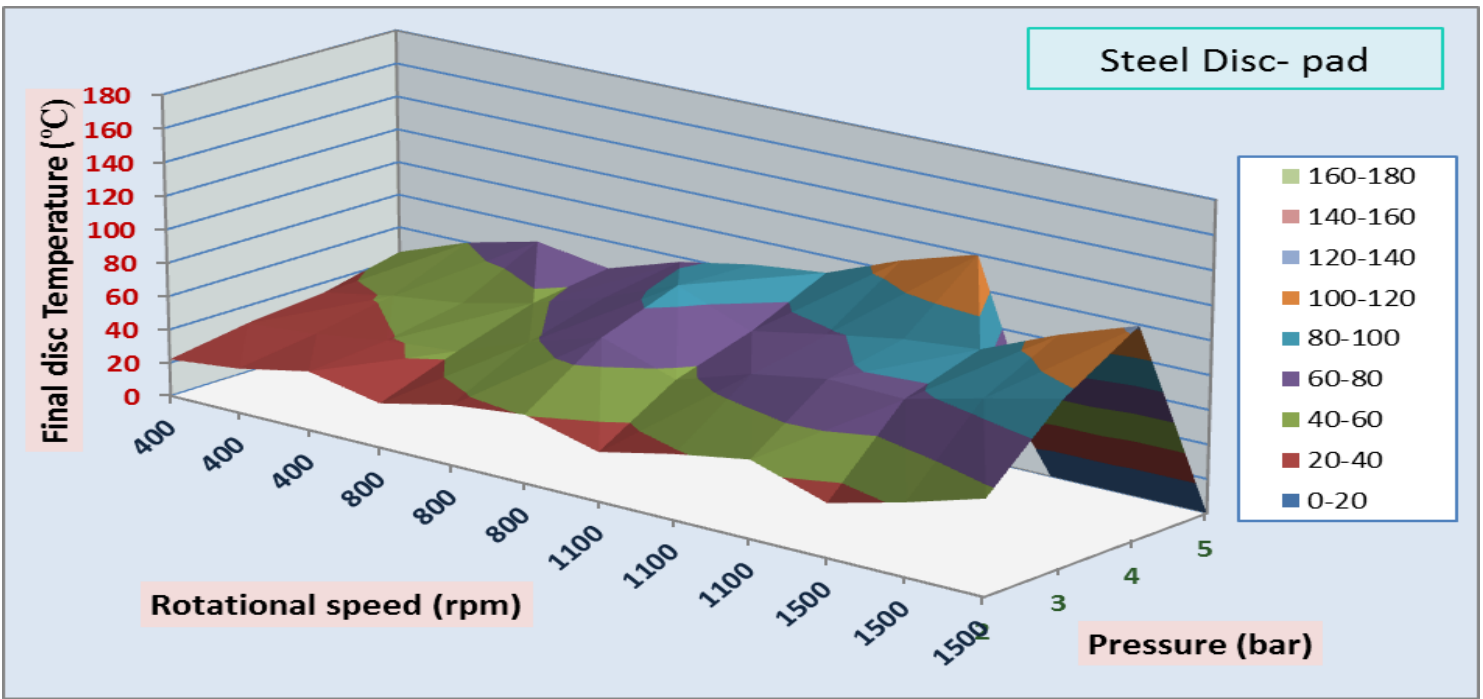

Figure 14. Effects of both rotational speed and pressure on temperature of steel disc

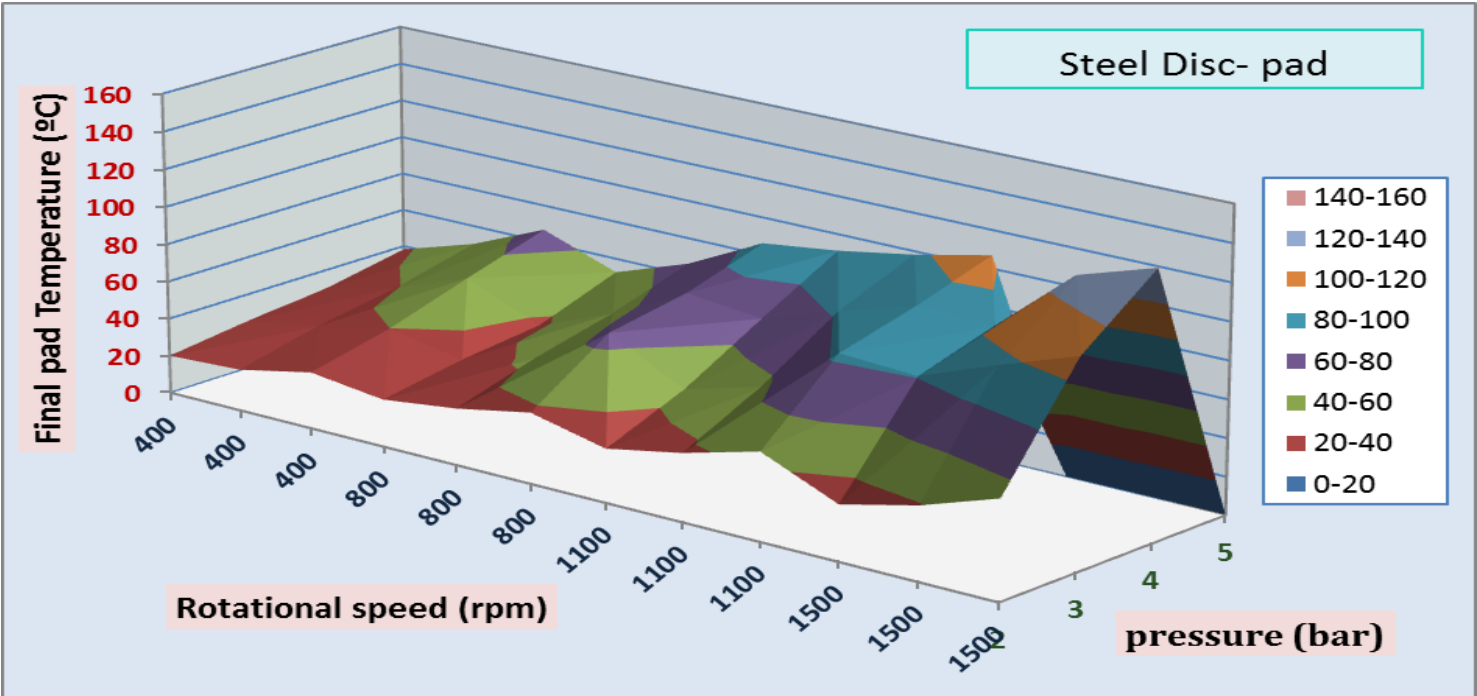

Figure 15. Effects of both rotational speed and pressure on temperature of pad 


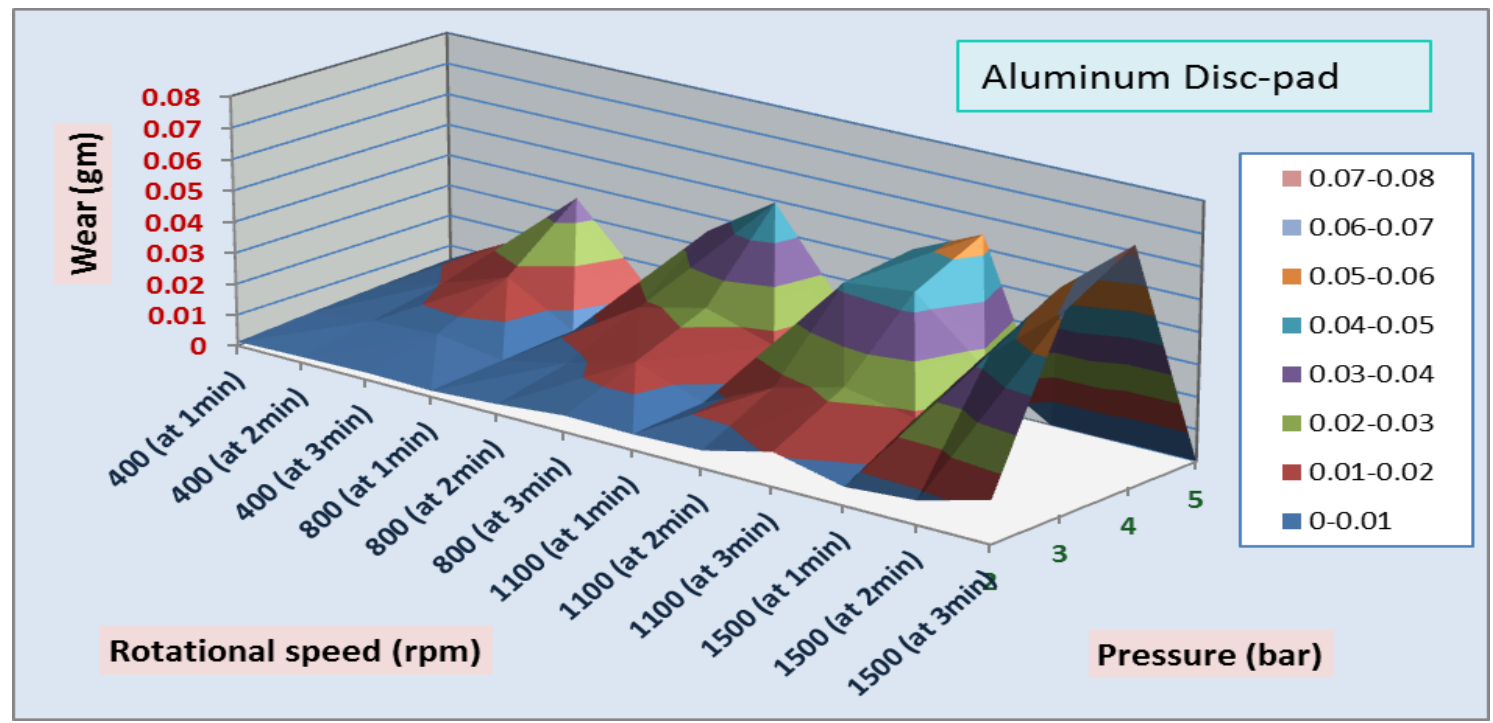

Figure 16. Effects of both rotational speed and pressure on wear

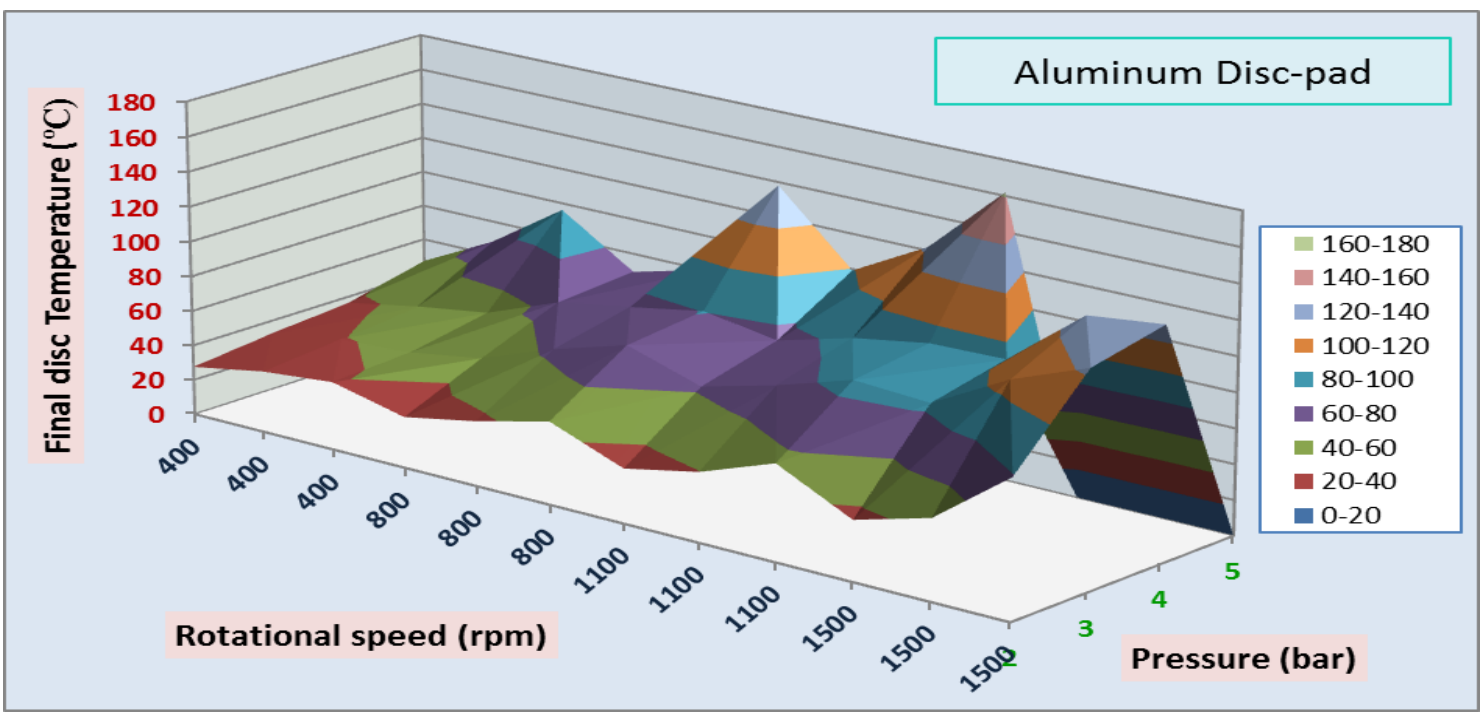

Figure 17. Effects of both rotational speed and pressure on temperature of aluminum disc

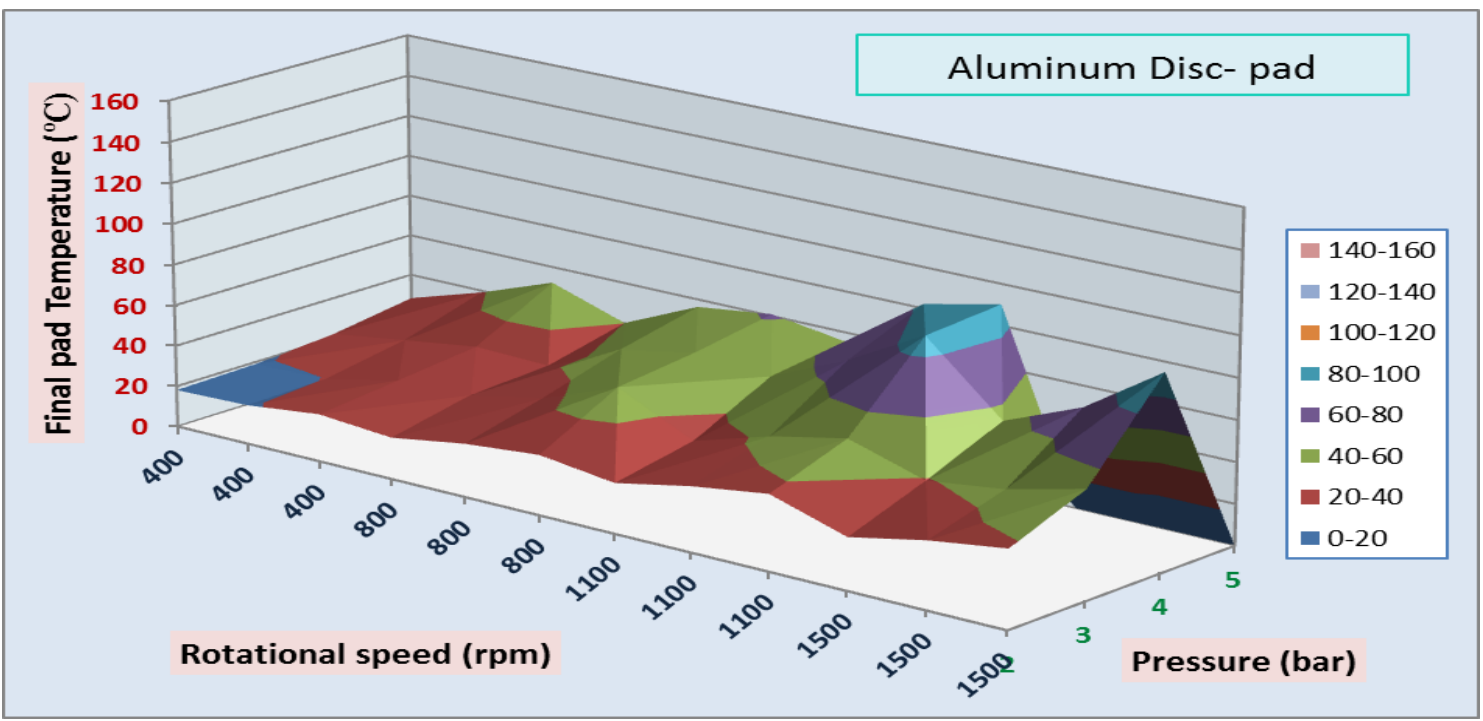

Figure 18. Effects of both rotational speed and pressure on temperature of pad 


\subsubsection{Comparison between wear of the pad contact with steel and Aluminum disc}

From the comparison between the results obtained from the aluminum and steel disc it was found that the wear debris in the pad much higher when the aluminum disc is used. The maximum weight loss in the pad as contact with aluminum at pressure equal 4 bar, rotational speed equal to $1500 \mathrm{rpm}$, and contact time of $3 \mathrm{~min}$ is $0.0742 \mathrm{gm}$, while the maximum weight loss when steel disc was used at the same conditions is equal to $0.0153 \mathrm{gm}$. The wear of the pad against aluminum disc is higher than against steel disc because aluminum metal is softer than steel metal. Therefore, the hard abrasive grains of the brittle pad have high penetrate in the softer material surface which leads to result high weight loss. On the other hand, the pad will wear rapidly with aluminum, while apparently protecting the aluminum [20]. It is obviously that at pressure 4, it is better to use an aluminum disc with pad at low pressure in the equipment required lightweight while it's better to use steel disc with the pad in the equipment where the wear is the problem as shown in figure 19.

Friction heating and the resulting contact temperatures can have an important influence on the tribological behavior and failure of sliding components. The interface temperature can become high enough to cause changes in the structure and properties of siding materials, oxidation of the surface, and possibly even melting of the contacting solids. It is very important to find out the temperature rise during the friction and find out the optimum choice of the material in the sliding components. Therefore, in this study, a comparison of friction temperature between the two discs made from aluminum and steel has been done. It was observed that aluminum disc has higher temperature than the steel disc at the same conditions as shown in figure 20 due to the high reduction in weight of pad when aluminum disc is used which reduce the capability of storing heat that resulting at high working temperature in aluminum disc. In addition, thermal conductivity of aluminum is higher than steel, therefore heat will generated due to the friction at the interface plan between discs and pad which is carried away much faster by aluminum than steel. Moreover, the results showed that the pad have high temperature when it is contact with steel disc compared with aluminum disc as shown in figure 21 .

The results indicate that the effect of sliding speed on the wear behavior is smaller than for load. It is also indicated that the wear of pad starts low at low pressure and rotational speed for steel case and increased by a large amount at high pressure and rotational speed as exposed in figure 13. While, the wear starts with a quite high value even at the low conditions for aluminum case as present in figure 16.

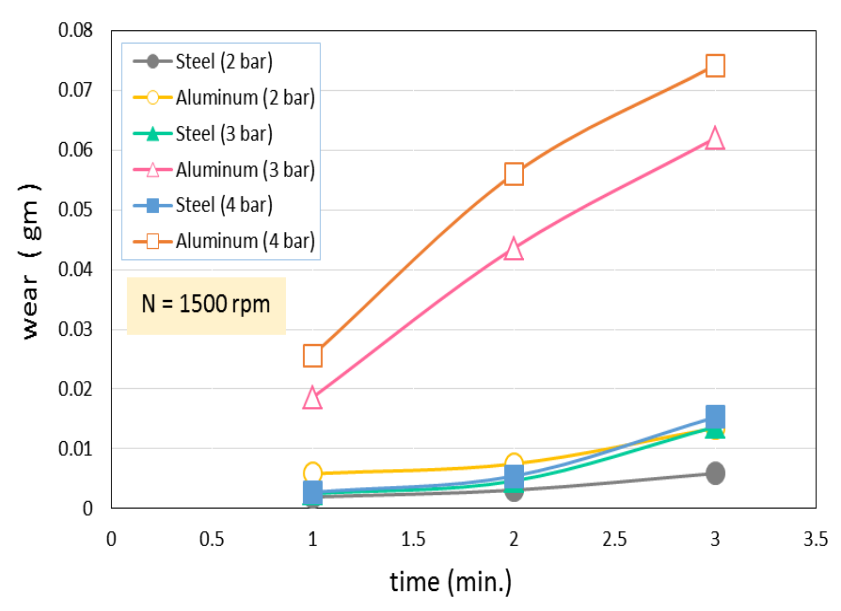

Figure 19. Comparison between wear of the pad with steel and with aluminum disc at rotational speed $1500 \mathrm{rpm}$

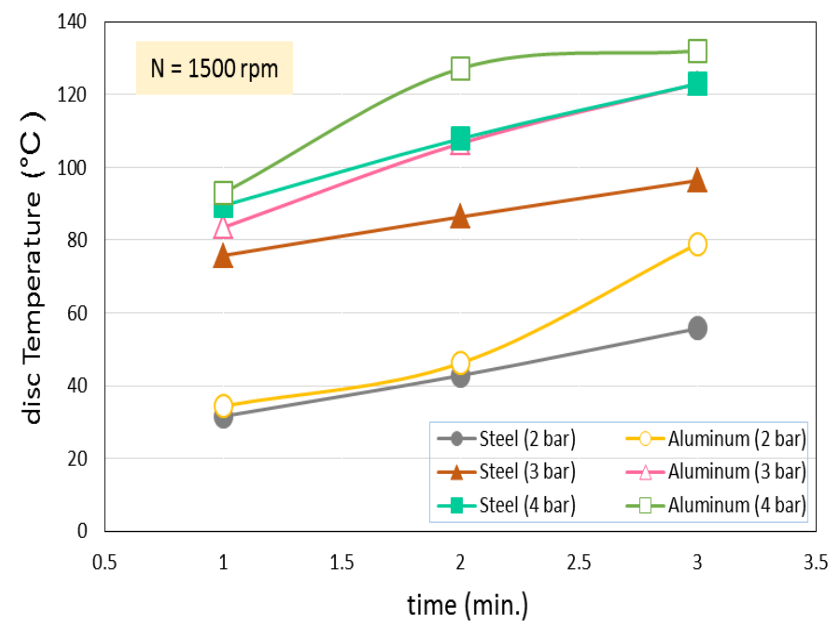

Figure 20. Comparison between steel and aluminum disc temperature at rotational speed $1500 \mathrm{rpm}$

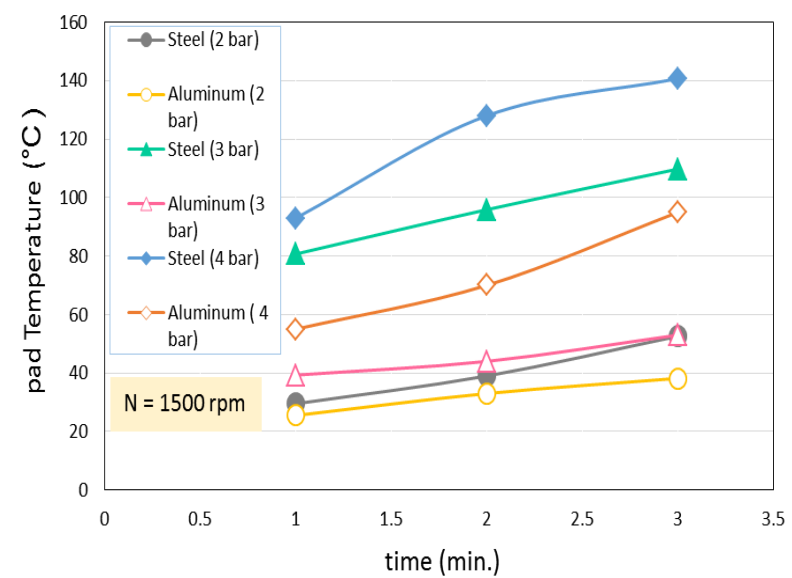

Figure 21. Comparison between temperature of pad with steel and with aluminum disc at rotational speed $1500 \mathrm{rpm}$ 


\subsection{Artificial Neural Network}

The final optimal structure of neural network model that used for steel disc is (5-7-8-3) which is shown in figure 5. The correlation coefficient of wear, and final temperature of steel disc and pad in this model is $0.99978,0.96789$ and 0.99141 for training respectively with mean square error 0.000024 , while $0.98964,0.9997$, and 0.9999 for testing respectively with mean square error 0.032 and training function (trainscg). The aluminum disc neural network model with two hidden layers were proposed, the optimal structure of this neural network model is also (5-7-8-3) with training function (trainseg). The correlation coefficient of training is $0.9999,0.9999$, and 0.9782 for wear, aluminum temperature, pad temperature, respectively with mean square error 0.000009 . In testing, the correlation coefficient is $0.9682,0.9013$, and 0.9998 for wear, steel temperature, pad temperature, respectively with MSE equal to 0.0101 . Figures 22,23 , and 24 show the comparison between the ANN model results and the experimental results of both aluminum and steel for wear, temperature of discs and temperature of pads respectively. Satisfactory agreement between the experimental and ANN results was obtained from using this type of neural network.

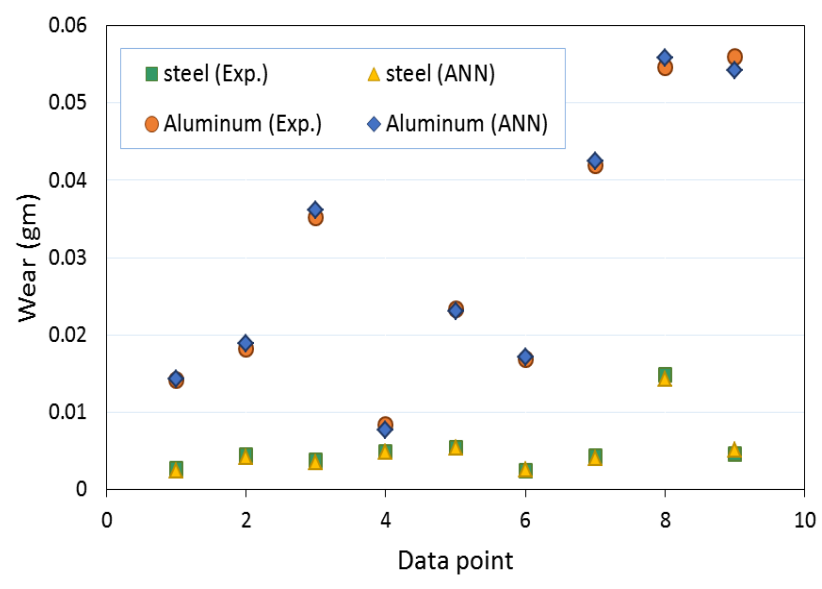

Figure 22. The experimental and predicted ANN model results of wear

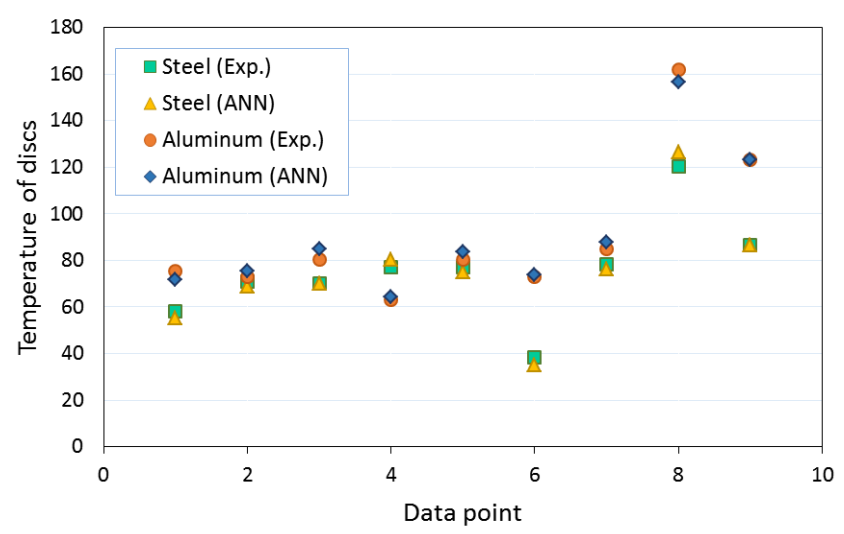

Figure 23. The experimental and predicted ANN model results of temperature of steel disc

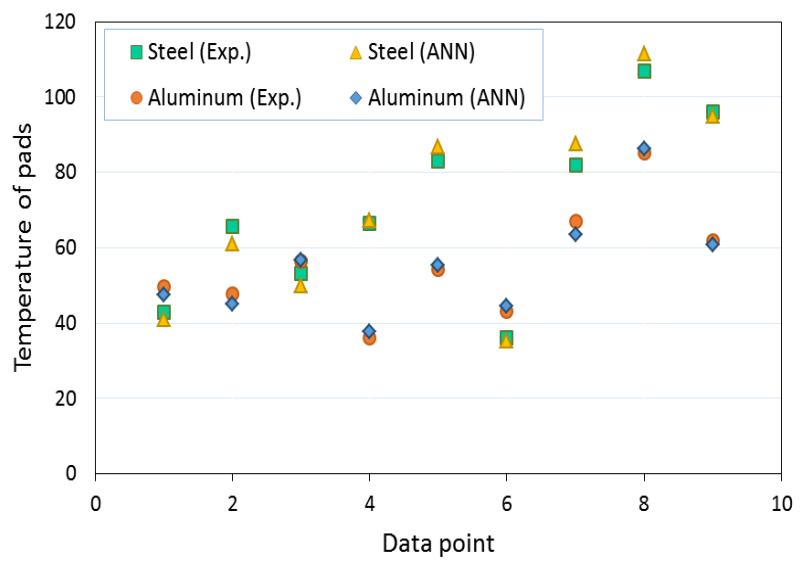

Figure 24. The experimental and predicted ANN model results of temperature of steel disc

\section{Conclusions}

From the results of the present study, the important conclusions are as follows:

1. The ANN with two hidden layer consist from 8 nodes in the first hidden layer and 7 nodes in the second with training function as conjugate gradient (trainscg) has been successfully used to predict the wear debres and friction temperature. The ANN model showed a reasonable agreement with the experimental results.

2. The wear debris in pad is much higher when the aluminum disc is used compared with steel disc.

3. It is better to use an aluminum disc with pad in the equipment work at low pressure, while the steel disc with the pad is more suitable to use in the equipment where the wear is the problem.

4. The contact time have a high effect on the wear followed by load and rotational speed.

5. The friction temperature increase when the load, rotational speed, and contact time increased. However, aluminum had higher friction temperature than the steel at the same conditions.

6. The pad has high temperature when it is contact with steel disc more than the aluminum disc.

\section{REFERENCES}

[1] Bharat Bhushan, Introduction To Tribology, The Ohio State University, USA, 2013.

[2] H J Meigh C Eng MIMechE, Resistance to Wear of Aluminum Bronzes, Cambridge University, 2000.

[3] Prasanta Sahoo, Engineering Tribology, PHI Learning private limited, 2005. 
[4] T. B. Asafa, D. A. Fadare, Artificial Neural Network Predictive Modeling of Uncoated Carbide Tool Wear When Turning NST 37.2 Steel, ARPN Journal of Engineering and Applied Sciences, Vol.7, No.4, 2012.

[5] Hülya Kaçar Durmuş, Erdoğan Özkaya, Cevdet Meri·ç, The Use Of Neural Networks For The Prediction of Wear Loss And Surface Roughness of AA 6351 Aluminum Alloy, Materials And Design,Vo.27, No.2, 2006.

[6] Nagaraj, A., Shivalingappa, D., Halesh Koti, Channankaiah, Modeling And Predicting Adhesive Wear Behaviour of Aluminium-Silicon Alloy Using Neural Networks, International Journal of Recent Scientific Research, Vol. 3, No. 5, 2012.

[7] S.Kalidass, P.Palanisamy, V.Muthukumaran, Prediction Of Tool Wear Using Regression And Artificial Neural Network Models In End Milling of AISI 304 Austenitic Stainless Steel, International Journal of Engineering and Innovative Technology (IJEIT), Vol.1, No.2, 2012.

[8] T Nasir, B F Yousif, S McWilliam, N D Salih, LTHui, An Artificial Neural Network For Prediction of The Friction Coefficient of Multi-Layer Polymeric Composites In Three Different Orientations, J. Mechanical Engineering Science, Malaysia, 22 july 2009.

[9] C.S Ramesh, R. Suresh Kumar, Mathematical and Neural Network Models For Prediction of Wear of Mild Steel Coated With Inconel 718 - A Comparative Study, International Journal of Scientific and Research Publications, Vol.2, No.7,2012.

[10] Pingjun Tao, Yuanzheng Yang, Xianchao Chen, Yuding He, Effect of Load on Surface Friction and Wear Behavior in ZrCuNiAl Bulk Amorphous Alloy, American Scientific Publishers, Vol.4, No.2, 2015.

[11] Riyadh A. Al-Samarai, Haftirman, Khairel Rafezi Ahmad, Y. Al-Douri, Effect of Load and Sliding Speed on Wear and Friction of Aluminum- Silicon Casting Alloy, International Journal of Scientific and Research Publications, Vol.2, No.3, 2012.

[12] M. Ramesh , T. Karthikeyan , R. Arun , C. Kumaari , P. Krishnakumar, M. Mohankumar, Effects of Applied Pressure on the Wear Behavior of Brake Lining Sliding Against Ferrous and Nonferrous Disc, International Journal of Advanced Mechanical Engineering, Vol.4 ,No.3 , PP.285-290, 2014.

[13] M. A. Chowdhury, D. M. Nuruzzaman, Experimental Investigation on Friction and Wear Properties of Different Steel Materials, Tribology in Industry, Vol.35, No.1, PP.42-50, 2013

[14] You wang, Xiao Dong Li, ZhenCheng Fen, The Relationship Between The Product of Load and Sliding Speed With Friction Temperature and Sliding Wear Of A 52100 Steel, Suipta Metallurgica et Materiali, Vol.33, No.7, 1995.

[15] A.Gaard, N. Hallback, P. Krakhmalev, J. Bergstrom, Temperature Effects on Adhesive Wear In Dry Sliding Contacts, Wear 268, Sweden, pp 968-975, 2010.

[16] Mohammed E. Haque, K.V.Sudhakar, Prediction For Dry Sliding Wear in P/M Alloy: A Back-Propagation ANN Approach, ORAL, USA, 2012.

[17] Dewan Muhammad Nuruzzaman, Mohammad Asaduzzaman Chowdhury," Friction Coefficient and Wear Rate of Copper and Aluminum Sliding against Mild Steel", International Transaction Journal of Engineering, Management, \& Applied Sciences \& Technologies, Vo.4, No.1, 2013.

[18] D. Murali Mohan Rao, Dr. C. L. V. R. S. V. Prasad, T. Ramakrishna, Experimental and Simulated Studies on Temperature Distribution for Various Disc Brakes, IJRMET, Vol.3, No.1, Nov-April 2013.

[19] Harbansh Singh, M. S. Sethi, O. S. Bhatia, Wear Rate Analysis of Hydrodynamic Journal Bearing In Different Conditions, International Journal Of Modern Engineering Research (IJMER), Vol.4, No.10, 2014.

[20] U. Pamuk, M. Baydogan, B. Nilufer , H. C imenoglu, An Energetic Approach To Abrasive Wear Of A Martensitic Stainless Steel, Scripta mater,Vo.42, No.9,2000.

[21] T. Hariprasad, D. Shivalingappa, A. Nagaraj, Geetha Manivasagam, The Use of Artificial Neural Network For The Prediction of Wear Loss of Aluminium-Magnesium Alloys, Int. J. Computer Aided Engineering and Technology, Vo.7, No.1, 2015. 